\title{
The Summer Plateau Low Pressure System of Mexico
}

\author{
DONNA F. TUCKER \\ Department of Physics and Astronomy, University of Kansas, Lawrence, Kansas
}

(Manuscript received 21 July 1997, in final form 22 May 1998)

\begin{abstract}
Average July heights and winds over a 10-yr period are computed at $850 \mathrm{mb}$ over Mexico using both surface and radiosonde data. During the day central Mexico at this level is dominated by low pressure, with some smaller areas of high pressure. The pressure systems were less pronounced in 1990 and the smaller high pressure areas were notably weaker during 1993 , showing that there is important interannual variability in these patterns. At night, the low pressure weakens and there are generally expanded areas of high pressure.

This area of low pressure is caused by the high plateau, which acts as an elevated heat source for the atmosphere during the day. Thus, the circulation is an extension of a similar one previously observed in the United States and is of about the same magnitude. Although computation of 850 -mb heights from surface data helps improve horizontal resolution at this level, additional data would be needed to assess the vertical structure of the plateau circulation system as well as to provide more details on the diurnal variations.
\end{abstract}

\section{Introduction}

The relationship between the atmospheric circulation patterns of Mexico and the southwest United States during the summer season has been the subject of a number of studies. Hales (1972, 1974) and Brenner (1974) showed that precipitation in Arizona during the summer was often related to surges of moist air moving into the region from northern Mexico. Carleton (1986) supported this view from analysis of cloud cover. Douglas et al. (1993) noted that the warm season precipitation maximum in the southwestern United States was actually the northern extension of a more intense maximum centered in northern Mexico. Summer is an important season in this region. At least $60 \%$ and in many areas $70 \%$ of the annual precipitation in western Mexico falls during the summer season (Douglas et al. 1993). This paper will investigate the low-level circulation in Mexico during July and will briefly look at its interannual variability and interaction with the low-level circulation in the western United States.

Studies of the atmospheric circulation in Mexico have been hampered by the relative lack of meteorological observations in that region in comparison with the United States. Two methods have recently been used to cope with this problem. One has been to supplement existing observations with additional ones for a short period of

Corresponding author address: Prof. Donna F. Tucker, Department of Physics and Astronomy, University of Kansas, Lawrence, KS 66045-2151.

E-mail: tucker@phoenix.phsx.ukans.edu time. Douglas and Li (1996) were able to use the Southwest Area Monsoon Project (SWAMP) data of 1993 to document substantial diurnal variations in atmospheric circulation patterns in this region. They were able to verify the presence of southerly flow over the Gulf of California and low pressure near the surface in the southwestern United States. Their study area did not include the higher terrain in this region and interactions of the circulation with the orography remain uncertain. The disadvantages of this method are that the locations of the observations may not detect all important meteorological features or that the period of enhanced observations may not have observations representative of typical situations in that region. An alternative method is to use numerical models to produce fields that would be dynamically consistent with the existing data. $\mathrm{Nu}$ merical models have had difficulty representing the lowlevel flow in this region (Dunn and Horel 1994a,b; Giorgi 1991; Giorgi et al. 1994). Stensrud et al. (1995), however, used a series of numerical model runs for consecutive time periods with four-dimensional data assimilation of the available data including the SWAMP data from 1990. They showed that when a numerical model used a dataset that included supplemental observations it could represent many of the observed features in this region. In another modeling study Stensrud et al. (1997) showed that the surges of moist air northward from the Gulf of California into the southwestern United States were favored when a midlatitude trough passes the western United States a few days before a tropical easterly wave arrives in the Gulf of California. Since enhanced observations are necessary for a good model simulation, 
this method is also as good as the representativeness of the observing period.

Neither Douglas and Li (1996) nor Stensrud et al. (1995) included analyses of the pressure field. It is possible that they considered the pressure data too sparse to conduct a valid analysis. The sea level pressure analysis from model output of Stensrud et al. (1997) showed high pressure over north-central Mexico but did not have any observations to verify its existence. The model output showing the sea level pressure was only for 1 day and the high pressure could be a result of model extrapolation to sea level in regions of high surface elevations. Rowson and Colucci (1992) found evidence of low pressure over central Mexico at $850 \mathrm{mb}$. Their analysis at $850 \mathrm{mb}$ included only three Mexican radiosonde stations, only one of which was at high elevations. Thus, previous investigators do not agree on a fundamental point: whether the lower levels of the atmosphere over Mexico are dominated by high or low pressure during the summer. This issue is an important one because the pressure systems will influence the wind field, low level convergence patterns, and the precipitation patterns as well.

Tang and Reiter (1984, hereafter TR) used the 850$\mathrm{mb}$ surface to examine the seasonal variation of atmospheric boundary layer circulation over areas of high elevation in the United States and Tibet. They showed that the western United States was dominated by relatively low pressure at $850 \mathrm{mb}$ during the summer. This situation occurs at this time of year because the solar radiation reaching the earth's surface is strong and the high terrain acts as an elevated heat source. Tang and Reiter (1984) presented evidence that the seasonal variation of the pressure systems was related to seasonal precipitation distribution. Reiter and Tang (1984) showed that during the summer the plateau circulation system undergoes diurnal variations that explain some of the diurnal precipitation patterns in this region. Tucker (1993) established that the plateau circulation system could interact with local circulations in places to produce more complex diurnal precipitation patterns. Only extreme northeastern Mexico was included in TR's study domain, and they did not consider whether the plateau circulation extended south of the United States border. It would seem reasonable that the Mexican region, which has substantial areas of elevated terrain (Fig. 1), could also force the development of low pressure in the atmospheric boundary layer. On the other hand, Mexico is located between two oceans, the distance between which becomes smaller as one proceeds farther south. The oceans would provide a stabilizing influence on temperatures and could prevent a plateau circulation system from developing. Since upper-air observations in Mexico are relatively sparse, it would be difficult to investigate this possibility from radiosonde data alone. The method used by TR, however, is heavily dependent on surface observations. As described below, it involves calculating $850-\mathrm{mb}$ heights from surface pressure using the hypsometric equation. Mexico does have a much larger number of surface stations, most of which make measurements of atmospheric pressure. Therefore, this paper will describe the results of an investigation examining the possibility of a summer plateau circulation system over Mexico using the method recommended by TR. The dataset and the methodology will be described in section 2 and the results presented in section 3. Section 4 will include conclusions and recommendations.

\section{Available data}

A study period from 1986 to 1995 was used and the month of July was selected as being the most representative of the summertime situation. The Mexican stations have a lot of missing data, and stations for which only a few days of data were available could be strongly biased toward a situation that was not representative of the entire month. In addition, the data records were somewhat noisy and included data that were obviously in error. These errors often appeared to be typographical errors but no attempt was made to correct them. Station pressures that would result in a pressure change of more than $10 \mathrm{mb}$ in $12 \mathrm{~h}$ were considered to be missing. Geopotential heights and temperatures were compared with data taken $24 \mathrm{~h}$ previously. Data for which the $24-\mathrm{h}$ changes were greater than $60 \mathrm{~m}$ or $10^{\circ} \mathrm{C}$ were considered to be missing. For both surface and upper-air data there needed to be at least 19 observations at a given time in a month or the data for that station for that month and time were not used. With at least $60 \%$ of the days represented, data from the station should be representative of that of the entire month. To avoid biases from a particular year the station had to have useable data for at least 6 out of the $10 \mathrm{yr}$ to be included in the dataset. Data for a corresponding period in the United States are included for geographic continuity. Station pressures at some U.S. stations were computed from altimeter settings. The locations of all stations in the dataset can be seen in Fig. 2. Note that some Mexican stations did not have standard three-letter station identification. For these stations, three-letter identifications were created for this project.

For upper-air stations, some stations reported only at 0000 UTC, some stations reported only at 1200 UTC, and some stations reported at both times. Which stations fell into which category varied from year to year. The 0000 and 1200 UTC times were handled separately so that more observations at one time or another did not bias the monthly averages. A total of eight upper-air stations [including Belize City (ZBZ)] are in the dataset. Data from radiosonde stations in the southwestern United States are also included for comparison and geographical continuity.

Heights at $850 \mathrm{mb}$ were calculated for surface stations whose elevations were above $900 \mathrm{~m}$. Tang and Reiter (1984) used stations with elevations greater than 700 


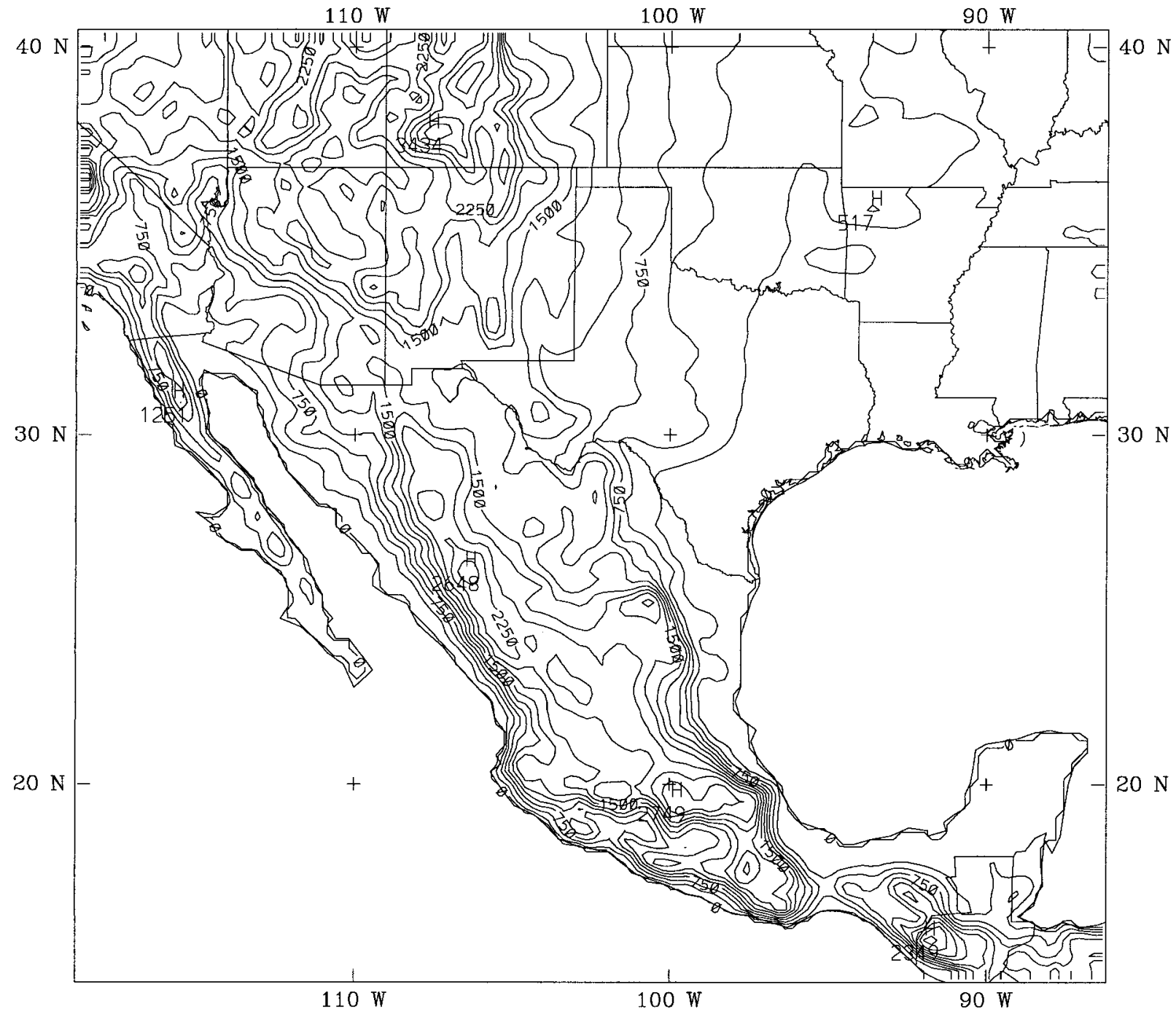

FIG. 1. Surface elevation in Mexico. Elevations were interpolated from a 10-min lat-long grid to a 27-km grid on a Mercator projection. Contour lines drawn every $250 \mathrm{~m}$.

m. Mexico did not have any stations between 700- and 900-m elevation with reliable enough data to be useful. At $900 \mathrm{~m}$ the average pressure would be slightly greater than $900 \mathrm{mb}$. An error in the average temperature of 2 $\mathrm{K}$ would produce an error in the computed heights of about $5 \mathrm{~m}$, which is half of the contour interval used to present results in this paper. Thus for stations lower than $900 \mathrm{~m}$ it was deemed that the method of TR, described below, would produce $850-\mathrm{mb}$ heights with an unacceptable amount of error. For most surface stations, data were fairly reliable in that they had tolerable amounts of missing data for 0000 and 1200 UTC but data at other times were more sparse. Thus only 0000 and 1200 UTC are included in this study since other times do not have enough data for analysis. Station elevation data for some stations were not reliable. For two stations in this study, Chilpancingo (CHL) and Comitan (CMT), station elevations were determined from de- tailed topographic maps. The error in the 850-mb heights computed at these stations is most likely higher than at other stations. The data are included in the analysis because they do yield some information in an area that otherwise has very little data. A total of 23 surface stations with elevations above $900 \mathrm{~m}$ have a sufficient number of observations at 0000 and 1200 UTC. Again these are supplemented with surface data from stations in the southwest United States whose elevations are over $900 \mathrm{~m}$.

\section{Temperature and height fields}

\section{a. 10-yr average}

Heights at $850 \mathrm{mb}$ at 0000 and 1200 UTC were determined using the method described by TR. With this technique 850 -mb heights are computed at surface sta- 


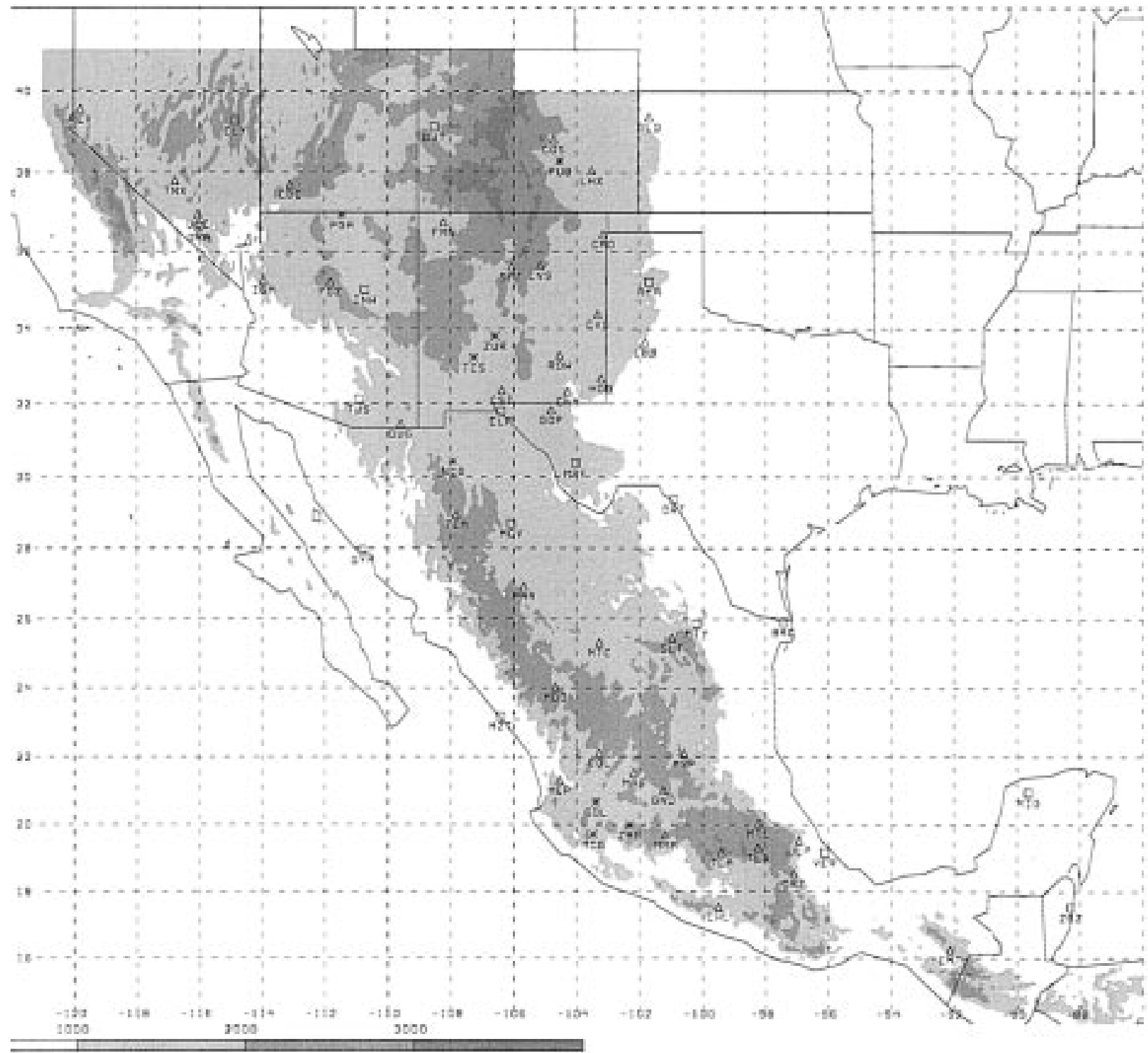

FIG. 2. Locations of stations with meteorological data. Three-letter identifiers are supplied for each station. Radiosonde stations are marked by a box. Stations with average surface pressures between 840 and $860 \mathrm{mb}$ are denoted by an asterisk. Other surface stations are labeled with triangles. Light shading indicates surface elevations between 1000 and $2000 \mathrm{~m}$. Medium shading is used for areas between 2000- and 3000-m surface elevation, and darkest shading for areas above 3000-m surface elevation.

tions from station pressure data using the hypsometric equation. The mean temperature of the layer between the station and $850 \mathrm{mb}$ is considered to be the arithmetic mean of the $850-\mathrm{mb}$ temperature and the surface temperature measured at the station. Here, $850-\mathrm{mb}$ temperatures are subjectively interpolated in space from both radiosonde temperature observations and surface temperatures at surface stations with average surface pressures between 840 and $860 \mathrm{mb}$. For the latter, the average surface temperature over the month was considered to be representative of the average $850-\mathrm{mb}$ temperature. Only four surface stations in Mexico could be used for this purpose. The station locations and their temperatures can be seen in Fig. 3. Note that since the surface pressure at Mexico City (MEX) is above 850 $\mathrm{mb}$ it does not have measured $850-\mathrm{mb}$ temperatures, even though it is a radiosonde station. Douglas and Li (1996) showed a steep temperature gradient at 0000 UTC at $850 \mathrm{mb}$ with increasing temperatures toward the interior of extreme northwestern Mexico but had no data over the central highlands. At 1200 UTC they showed much weaker temperature gradients. This situation would be expected if the plateau were acting as an elevated heat source. Thus the 850 -mb temperatures used at each surface station were, in many cases, heavily dependent on the radiosonde observations. Since the 
(a)

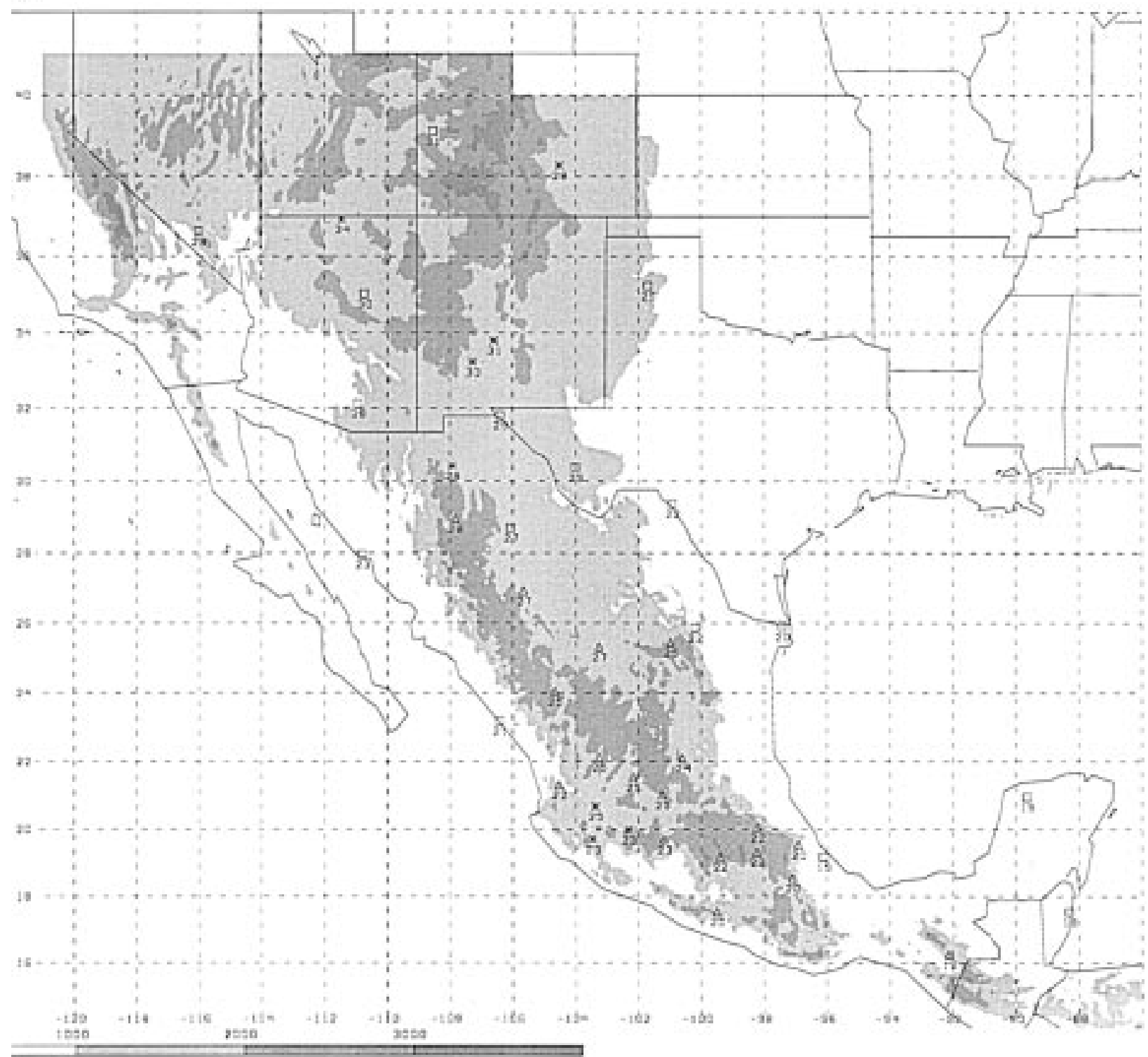

FIG. 3. Average temperatures at $850 \mathrm{mb}$ for $10 \mathrm{yr}$ of Jul (1986-95). Average surface temperatures of stations with surface pressures between 840 and $860 \mathrm{mb}$ are included as average 850 -mb temperatures (stations denoted by asterisk). Radiosonde stations are marked by a box.

radiosonde stations were mostly along the coast, the 850 -mb temperature may have been slightly underestimated for some stations at 0000 UTC. At 1200 UTC the $850-\mathrm{mb}$ temperatures from the surface stations would be at the bottom of the boundary layer, whereas at the coastal stations $850 \mathrm{mb}$ would be above the nocturnal boundary layer. It is possible that this situation resulted in errors in determining the average temperature of the $850 \mathrm{mb}$ to surface layer but the sign of this error cannot be determined without more information about the height of the boundary layer and the strength of the nighttime inversion. For stations with average surface pressure below $850 \mathrm{mb}$ (15 of them) such an error would result in an overestimate of the $850-\mathrm{mb}$ height at 0000 UTC. The computations of $850-\mathrm{mb}$ heights, however, are not very sensitive to this parameter. The $850-\mathrm{mb}$ heights are calculated from the hypsometric equation for 1200 and 0000 UTC with a mean temperature equal to the average of the surface temperature and the interpolated $850-\mathrm{mb}$ temperature.

The resulting 10-yr July mean 850-mb maps for 0000 and 1200 UTC are presented in Fig. 4. Resultant winds at $850 \mathrm{mb}$ are shown for the radiosonde stations and at the surface for stations with only surface data. There are substantial diurnal variations in the height field. These diurnal variations occur because the plateau acts 
(b)

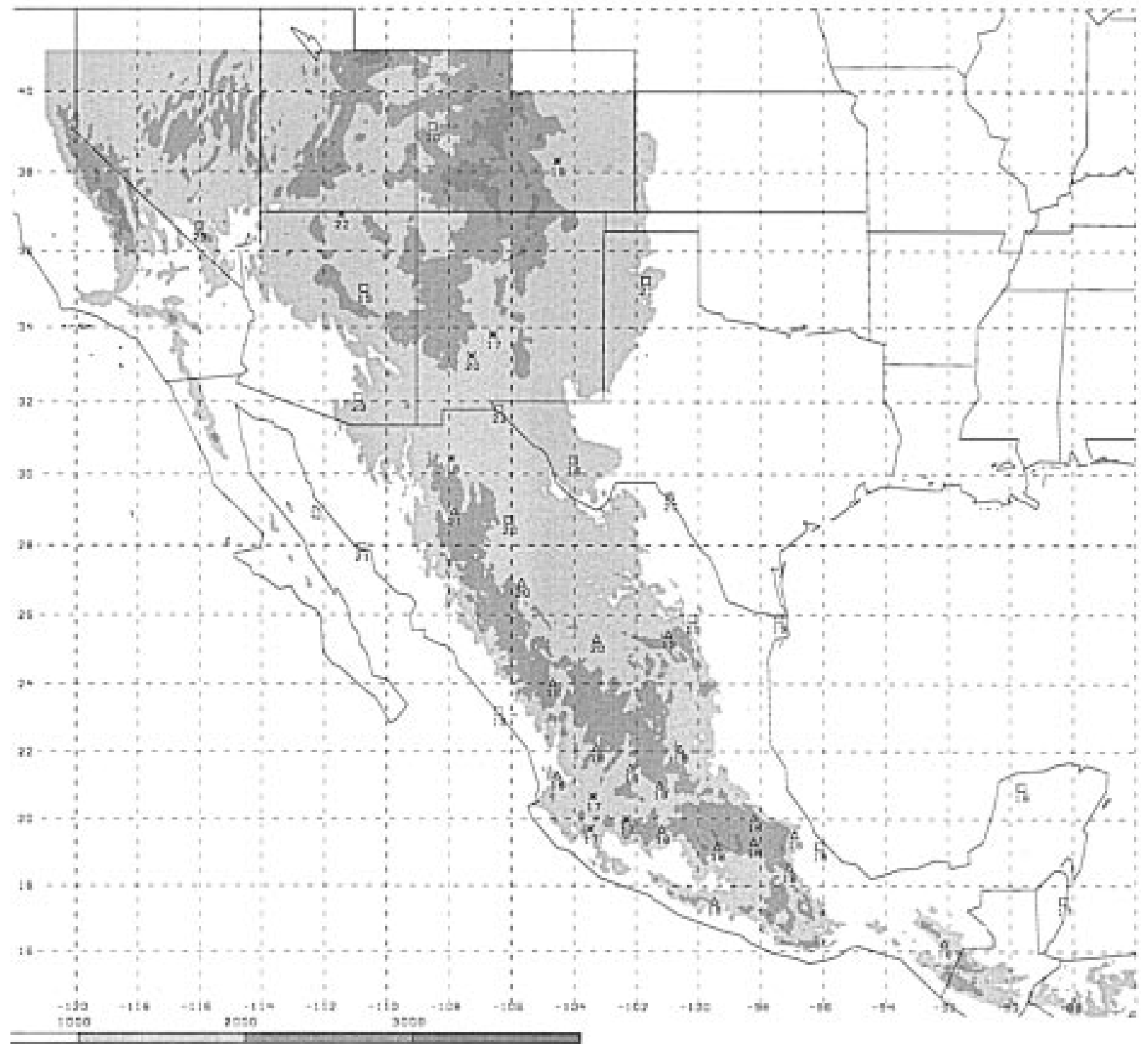

FIG. 3. (Continued) Stations with locations given by a triangle have interpolated 850 -mb temperatures. Surface elevations are denoted by shading as in Fig. 2: (a) 0000 UTC, (b) 1200 UTC.

as a strong elevated heat source during the day and a weaker heat source, or even a cold source, at night. A Student's t-test was used to check for differences in heights between 0000 and 1200 UTC at each radiosonde station and month. For $71 \%$ of the months for which both 0000 and 1200 UTC 850 -mb heights were available, the differences between the observations at these times were statistically significant $(\alpha<0.5)$. At the mountain stations of Mexico City (MEX) and Chihuahua $(\mathrm{MCV})$ the differences were always statistically significant. Variances at one time for one month were generally quite small (Table 1) indicating that the diurnal variances generally exceeded day-to-day ones. The small variances would indicate that the overall quality of the data used for this study was fairly high.

At 0000 UTC there are low heights in the center of the plateau in central Mexico extending south to at least $23^{\circ} \mathrm{N}$. Note that the center of this low pressure system in Mexico appears to be cut off from the one in the United States. Heights increase from the center of the Great Basin south to the Mexican border but in central Mexico they begin to decrease again. The topography on the United States-Mexico border is lower (Fig. 1) and thus there are higher heights in that area because the influence of the plateau as an elevated heat source would be less in this region. Although this area of rel- 
(a)

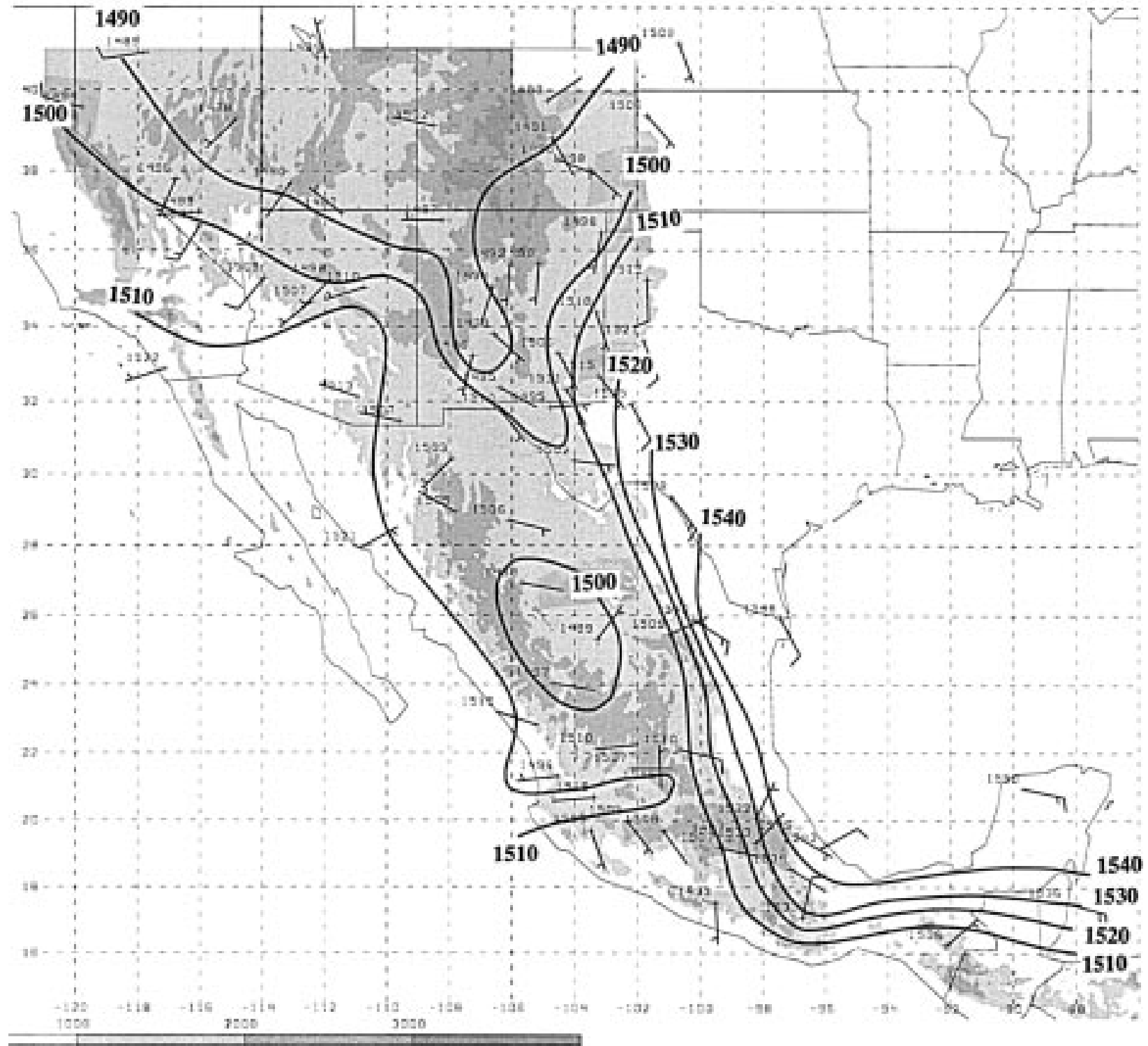

FIG. 4. Average 850-mb heights for $10 \mathrm{yr}$ of Jul (1985-95) from both radiosonde and surface data. Height contours are subjectively drawn every $10 \mathrm{~m}$. Winds are $850-\mathrm{mb}$ winds for radiosonde stations and surface winds for stations reporting surface data only. Surface elevations denoted by shading as in Fig. 2: (a) 0000 UTC, (b) 1200 UTC.

atively high pressure is somewhat larger, it is similar to a feature farther south in Mexico that is discussed below. Thus the overall summer daytime plateau circulation system of North America has embedded mesoscale features. It is not one of continuous decreases outward from two or three central points such as that represented by TR but has at least two central regions with an increase in heights between them. Because one of the areas of relatively high pressure happens to lie along the United States-Mexico border, the unity of the entire structure has been difficult to discern. Douglas and Li (1996) found evidence in the wind field at $850 \mathrm{mb}$ at $0000 \mathrm{UTC}$ of relatively high pressure over the lowlands of extreme northwest Mexico. The overall 0000 UTC 850-mb map of Mexico presented here shows that this feature would be a high relative to the low pressure over the plateau. Based on the 0000 UTC map presented here it is suggested that this high pressure area is part of a larger system located near the United States-Mexico border. In examining the wind fields it should be noted that this is a region of very complex terrain and that there are influences on the wind field that are of a smaller scale 
(b)

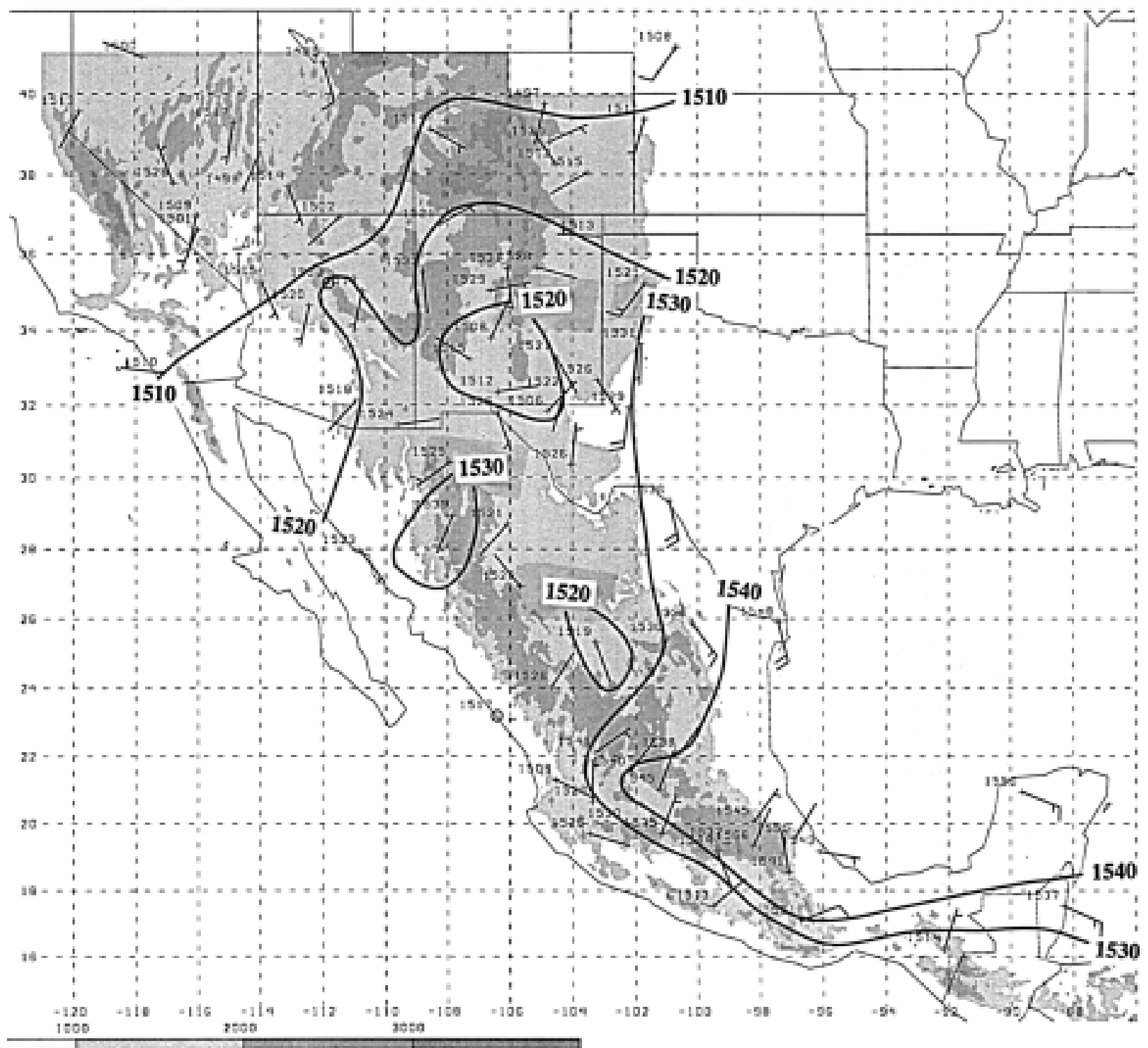

FIG. 4. (Continued)

TABLE 1. Average variance of 850 -mb heights $\left(\mathrm{m}^{2}\right)$ for the month of Jul for radiosonde observations.

\begin{tabular}{ccc}
\hline \hline Station & 0000 UTC variance & 1200 UTC variance \\
\hline GYM & 57.0 & 31.7 \\
MCV & 72.6 & 49.9 \\
MEX & 39.9 & 19.2 \\
MID & 41.4 & 37.9 \\
MTY & 104.1 & 71.4 \\
MZT & 46.2 & 49.6 \\
VER & 79.7 & 38.9 \\
ZBZ & 26.4 & 16.9 \\
\hline
\end{tabular}

than the large-scale height patterns shown here. Thus in places, the winds may not be geostrophic due to local forcing such as that which causes mountain-valley wind patterns.

Farther south in Mexico the terrain becomes more rugged and the pressure patterns are more broken up. Higher pressure is present over the lower elevations at $21^{\circ}-22^{\circ} \mathrm{N}$. This feature is consistent with the higher pressure found by TR over an area with a similar topographic pattern known as the Rawlins Gap in Wyoming. South of this region is another region of low pressure. Tepic (MEP), near the high pressure band, and Chilpancingo (CHL), south of the high pressure band, 
(a)

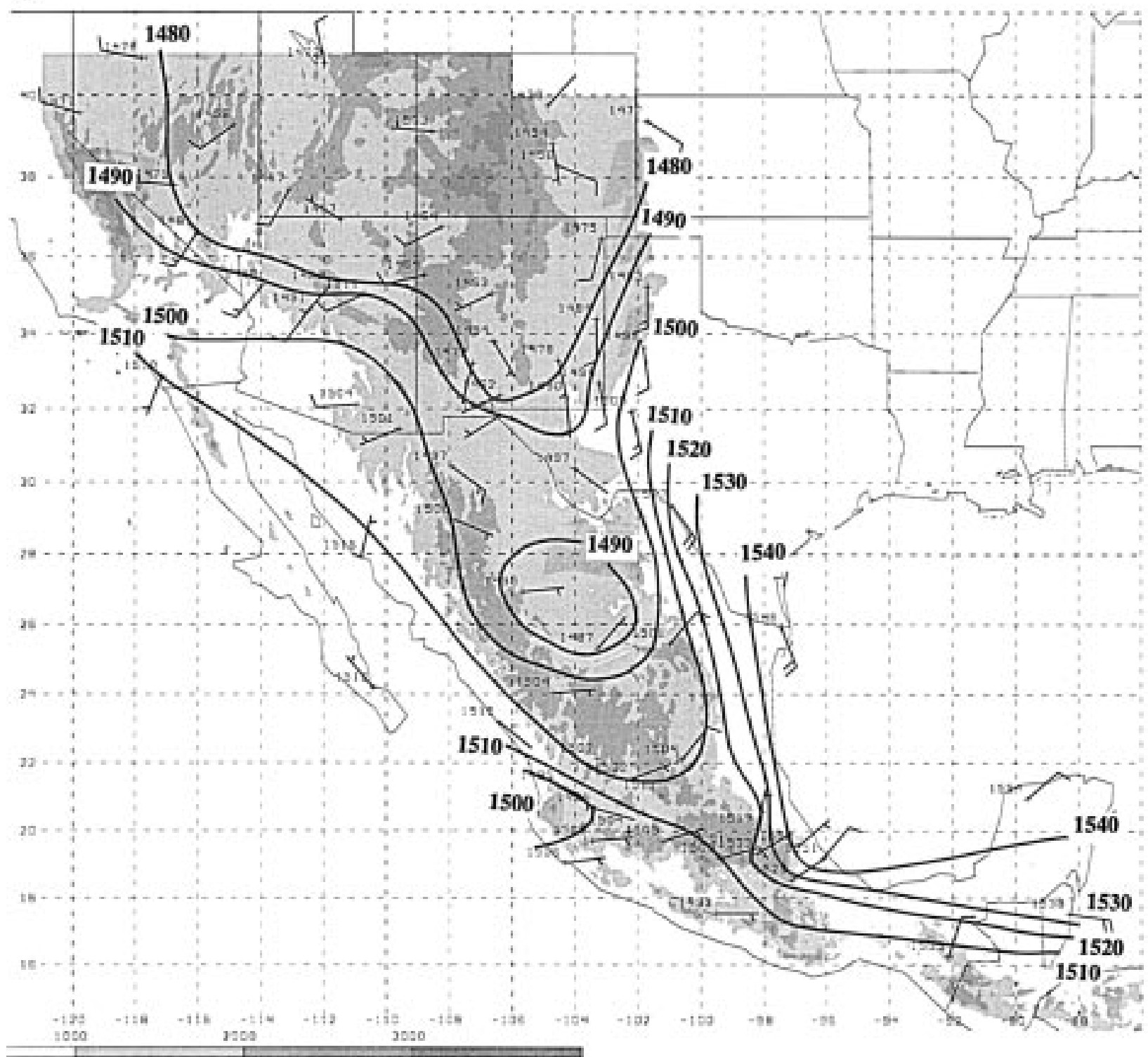

Fig. 5. Same as Fig. 3 with averages for Jul 1993 only.

both located near broad valleys, have notably low pressures. The lack of radiosonde observations near the coast and the greater proximity of the Atlantic and $\mathrm{Pa}$ cific Oceans make the overall plateau low difficult to confirm in the region south of $23^{\circ} \mathrm{N}$.

At 1200 UTC heights are relatively high compared with the coastal stations in north-central Mexico. The small regions of relatively high heights appear to have expanded with the low-height areas, which prevailed during the day, considerably shrinking in size. The wind shift at Empalme (GYM) since 0000 UTC would imply the dominance of relatively high pressure over northcentral Mexico. Since this station is in a region subject to surges that move northward (Stensrud et al. 1997), the average wind pattern could change if several strong surges occurred during the month. It is possible that problems of underestimating the 850 -mb heights at this time due to uncertainties in the temperature prevent the full depiction of the relatively high pressure in this region. This wind shift, brought about by the weakening low pressure over central Mexico, occurs in a region with a strong north-to-south moisture gradient (Stensrud et al. 1995). The 10-yr mean wind speeds are fairly weak because of the variability in the wind field. Further research will be needed to show whether stronger southerly winds due to a weakened plateau low exist at the time of moisture surges into the southwestern United States. 
(b)

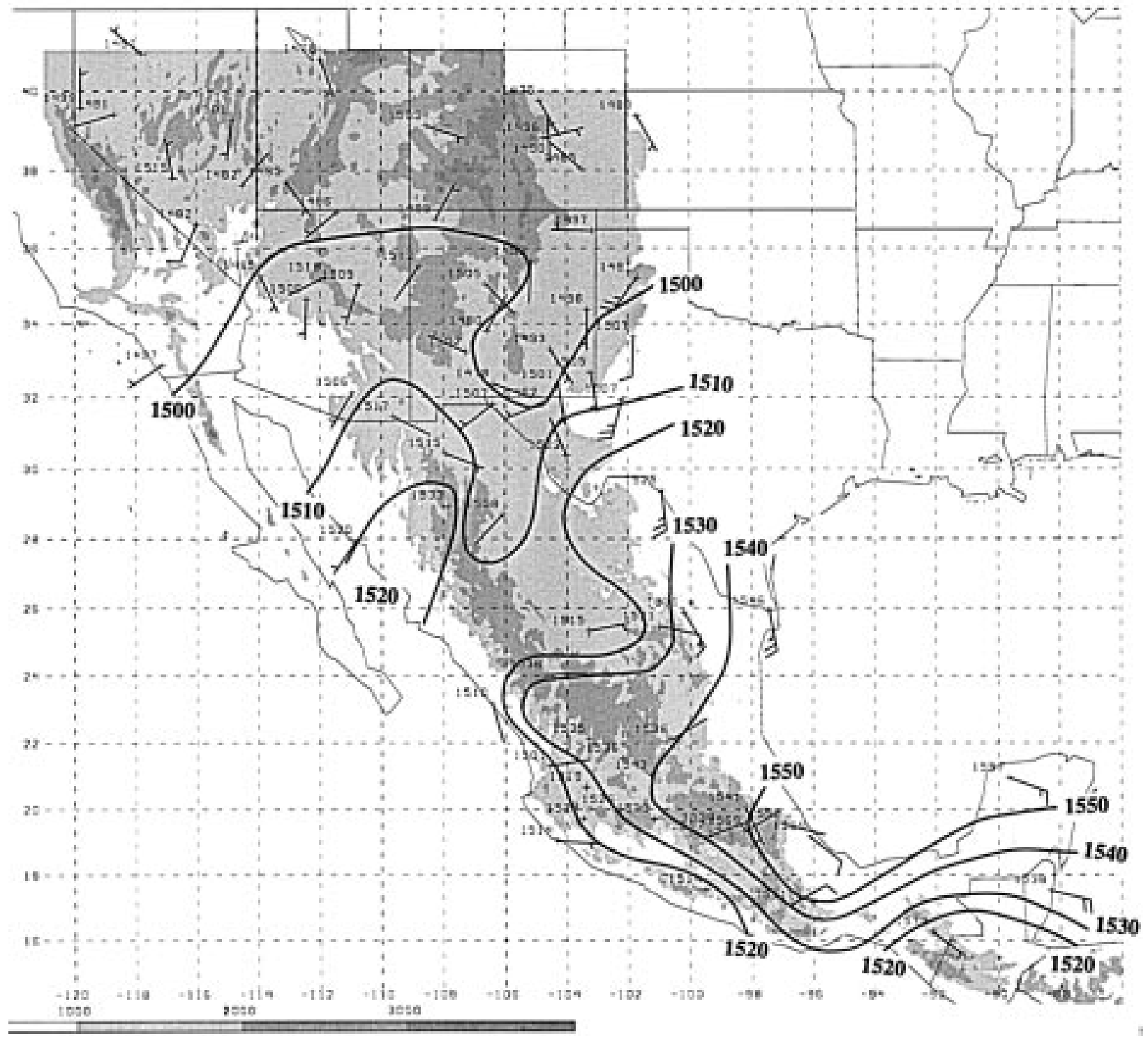

FIG. 5. (Continued)

\section{b. Interannual variability}

The interannual variability of the plateau circulation system in North America has not been explored. To get an idea of the interannual variability of these patterns, it will be useful to examine two years out of this dataset. The year 1993 is chosen since an analysis with more detailed data over northwestern Mexico is available (Douglas and Li 1996). Since it has previously been shown that plateau circulation systems are closely tied to precipitation patterns (TR), interannual variability in these systems would be related to those of precipitation. It was a dry year for most stations near the United States-Mexico border. For contrast, 1990 will also be examined since it was a wet year in the same region.
The mean 850-mb maps for July of 1993 are shown in Fig. 5. Overall heights tend to be lower in this year than in the 10-yr average. There is a stronger height gradient between central and eastern Mexico but not much difference in the gradient between central and western Mexico. The larger height gradient between central and eastern Mexico is significant because it would encourage southerly winds that are stronger than in the 10-yr mean in northern Mexico and the southern United States. These stronger winds could transport moisture northward to the Great Plains. This situation is notable because dry periods in the southwest appear to coincide with wet periods in the Great Plains (Higgens et al. 1997). The low pressure area over the northern plateau 
(a)

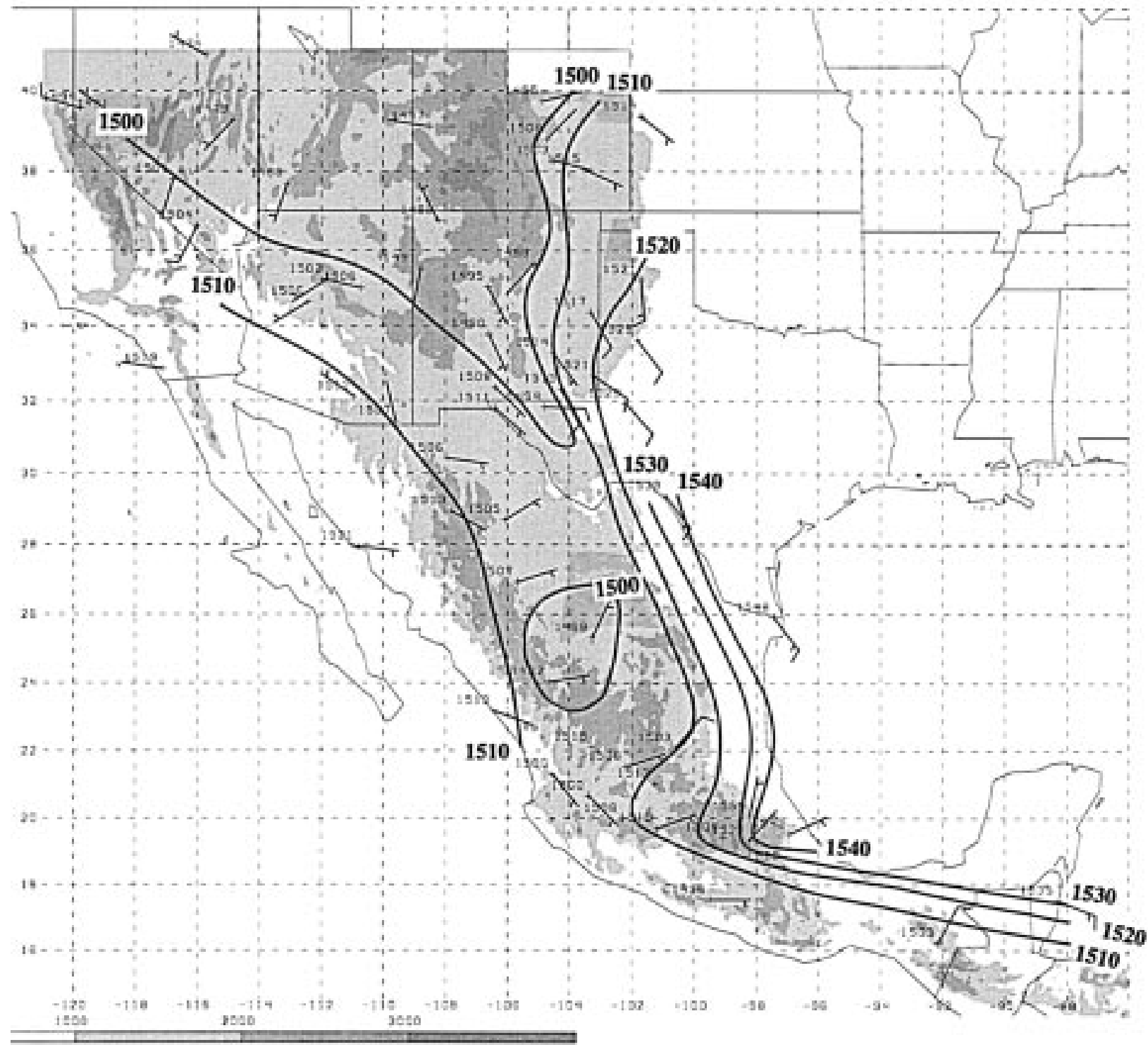

Fig. 6. Same as Fig. 3 with averages for Jul 1990 only.

of Mexico at 0000 UTC is broader and more nearly connected to the circulation system to the north in the United States. The high located at $21^{\circ}-22^{\circ} \mathrm{N}$ is greatly weakened with the low from Tepic (MEP) extending eastward. Likewise, mean winds at Tepic are easterly, showing that this pressure system is not significant in this year. At 1200 UTC the area of low heights over the plateau is very weak and the north-south pressure gradient more obvious. Note that the north-south pressure gradient would be associated with a more zonal component to the winds at the lower levels of the atmosphere. This would reduce moisture transport into the southwestern United States. The southerly winds in northwestern Mexico and the southern United States are even stronger at this time. This strengthening would be the result of nocturnal low-level jet formation processes. The small areas with relatively higher heights at 1200 UTC, which were present on the 10-yr average maps, are almost nonexistent here. Thus in 1993 the high pressure regions within the plateau circulation are weaker and the overall system is more continuous. The differences in the heights of the coastal stations between the 1990 (Fig. 6) and the 10-yr averages are less pronounced, revealing that the interannual variability is in the plateau circulation system and not a regional climate trend.

Conversely in 1990 the strength of the plateau low is weaker at 0000 UTC (Fig. 6) than in the 10-yr 0000 
(b)

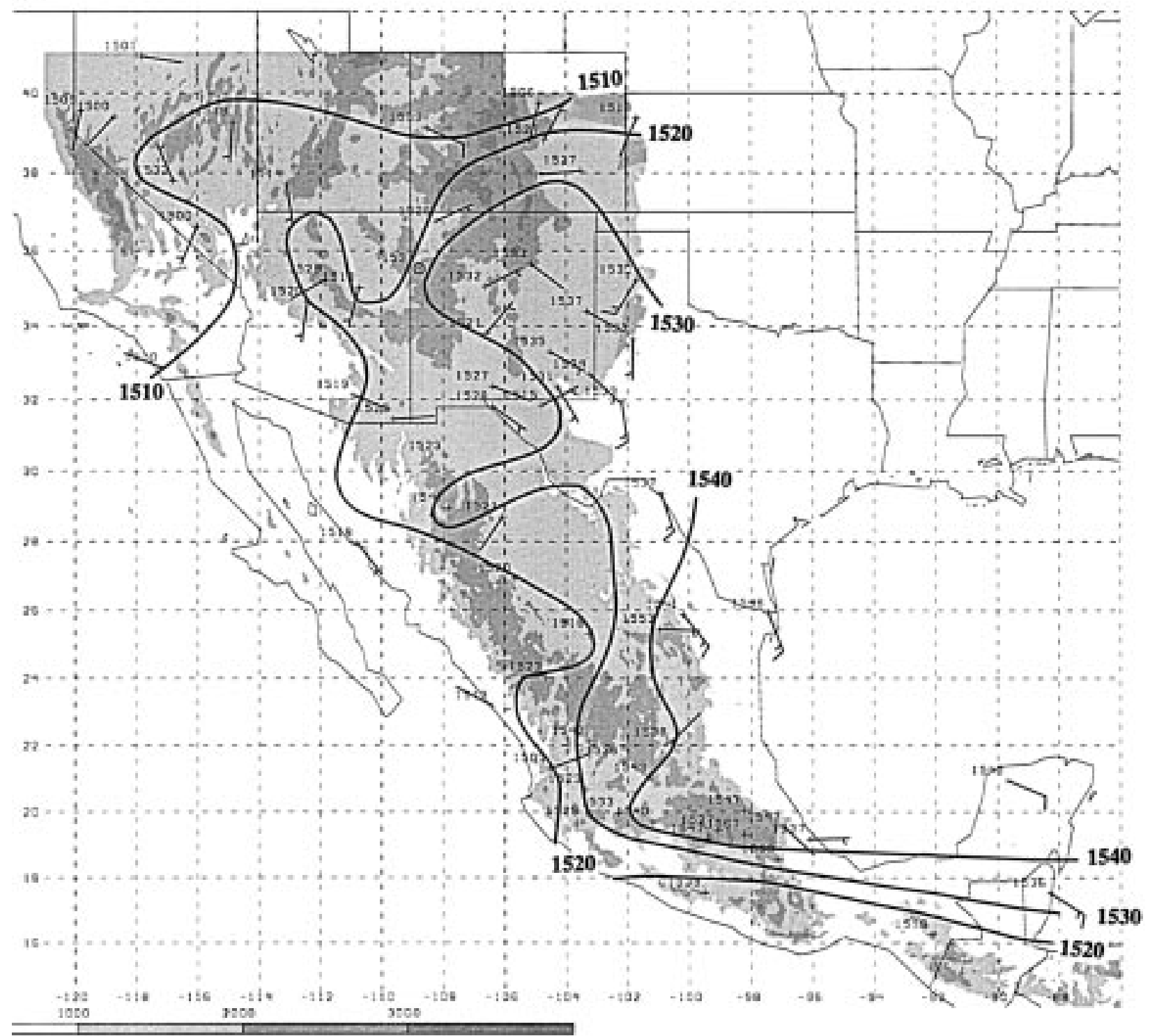

FIG. 6. (Continued)

UTC average, especially in the United States. Therefore, the north-south pressure gradient is weaker. East-west pressure gradients are weaker across Mexico as well. The area of high heights in Mexico around $21^{\circ}-22^{\circ} \mathrm{N}$ is not clearly present since the height field is ambiguous and there is no support for its presence in the wind field. This feature is not part of either of the two extremes of the circulation system. At 1200 UTC the height gradients are almost east-west (Fig. 6), as opposed to the north-south pattern evident in the 1993 averages. The height field seems to be more of a continuation of that farther east than for either the 10-yr average or the 1993 average. This height gradient would encourage the transport of moisture northward into the southwestern
United States. The center of the low heights is located farther south than in 1993, and the east-west pressure gradient and southerly winds in northeastern Mexico and the southern United States are somewhat weaker in 1990 than in the 10-yr average, especially at 1200 UTC. This area would likely experience reduced northward transport of moisture. Thus we can see that the physical basis for the negative correlation in the precipitation patterns between the southwestern United States and the Great Plains lies with the interannual variability of the plateau circulation system of Mexico.

The strength of the plateau circulation system of Mexico can be estimated from the average of the 0000 and 1200 UTC data. Although TR used data from 0300 and 
1200 UTC in their analysis, a rough comparison can be made. In their analysis the height gradient between the center of the plateau low and the central plains was 40 $\mathrm{m}$ over a distance of $1500 \mathrm{~km}$. The height gradient from the center of the low pressure area to the Mexican coast at $25^{\circ} \mathrm{N}$ latitude is $20 \mathrm{~m}$ over $625 \mathrm{~km}$. From this point of view, the plateau circulation system in northern Mexico is certainly comparable in magnitude to that in the United States and should be considered of equal importance.

\section{Conclusions}

The plateau circulation system of western North America is dominated by low pressure during the daytime hours of the summer season. The overall system is interrupted by smaller regions of relatively high pressure in areas of lower terrain. Because one of these regions is located along the United States-Mexico border, some previous authors have assumed that the plateau circulation system was predominantly located in the United States and ended near this border. This paper has shown that the plateau low extends into Mexico. During the nighttime hours the low pressure over the plateau weakens and expanded areas of relatively high pressure may appear.

Evidence is presented in this paper that in 1993 the small areas of relatively high pressure embedded in the main low pressure area were weaker and the overall circulation system more continuous. The year 1993 was a dry one for the southwestern United States and heights would indicate a reduced wind component across the moisture gradient. By contrast 1990, which had a weak plateau circulation, was a year with large amounts of precipitation in the southwestern United States. Work to further explore the relationship between the interannual variability of the plateau circulation system of North America and the precipitation patterns is ongoing. Variations in the strength of the plateau circulation system within a season will also be the subject of future research.

The pressure patterns presented in this paper are difficult to detect in the way conventional data have typically been analyzed. A large part of the problem has to do with the conversion of station pressure to sea level. The difficulties in making this adjustment have recently been summarized by Pauley (1998). Although using $850-\mathrm{mb}$ heights computed from station pressure has only been done for averaged data, the use of this technique for synoptic analysis has not been explored but deserves greater attention. Likewise, the use of such a method would also be possible in creating initial fields for numerical models. As pointed out by Stensrud et al. (1997) these models have had difficulty in representing atmospheric circulations in this region. The use of 850$\mathrm{mb}$ heights computed from station pressure would not require any additional observations, yet it holds the possibility of increasing the accuracy of forecasts. Most sigma coordinate models do not include the observations of surface pressure in their initial fields because the elevation of the model grid point is not necessarily the same as the analyzed elevation based on the elevations of surrounding stations.

Even if better forecasts can be achieved due to more extensive use of available data, studies of the circulations in this region are still greatly hampered by a relative lack of observations. Diurnal variations could not be thoroughly explored because of insufficient data at all times during the day. Likewise, the vertical structure of the plateau circulation system could not be investigated because few upper-air observations exist in the area. A greater density of observations in both space and time are needed to further the understanding of atmospheric circulation patterns in this part of the world.

Acknowledgments. This work was supported by the National Science Foundation under Grant ATM9622820. Assistance with computer programming was provided by Christopher Sramek, Xuandong Hua, and Lance Steele.

\section{REFERENCES}

Brenner, I. S., 1974: A surge of maritime tropical air-Gulf of California to the southwestern United States. Mon. Wea. Rev., 102, 375-389.

Carlton, A. M., 1986: Synoptic-dynamic character of 'bursts' and 'breaks' in the south-west U.S. summer precipitation singularity. J. Climatol., 6, 605-623.

Douglas, M. W., and S. Li, 1996: Diurnal variation of the lowertropospheric flow over the Arizona low desert from SWAMP1993 observations. Mon. Wea. Rev., 124, 1211-1224.

- R. A. Maddox, K. Howard, and S. Reyes, 1993: The Mexican monsoon. J. Climate, 6, 1665-1677.

Dunn, L. B., and J. D. Horel, 1994a: Prediction of central Arizona convection. Part I: Evaluation of the NGM and Eta model precipitation forecasts. Wea. Forecasting, 9, 495-507.

$\longrightarrow$, and — 1994b: Prediction of central Arizona convection. Part II: Further examination of the Eta model precipitation. Wea. Forecasting, 9, 508-521.

Giorgi, F., 1991: Sensitivity of simulated summertime precipitation over the western United States to different physical parameterizations. Mon. Wea. Rev., 119, 2870-2888.

- C. S. Brodeur, and G. T. Bates, 1994: Regional climate change scenarios over the United States produced with a nested regional climate model. J. Climate, 7, 375-399.

Hales, J. E., 1972: Surges of maritime tropical air northward over the Gulf of California. Mon. Wea. Rev., 100, 298-306.

_ 1 1974: Southwestern United States summer monsoon sourceGulf of Mexico or Pacific Ocean? J. Appl. Meteor., 13, 331342.

Higgins, R. W., Y. Yao, and X. L. Wang, 1997: Influence of the North American monsoon system on the U.S. summer precipitation regime. J. Climate, 10, 2600-2622.

Pauley, P. M., 1998: An example of uncertainty in sea level pressure reduction. Wea. Forecasting, 13, 833-850.

Reiter, E. R., and M. Tang, 1984: Plateau effects on diurnal circulation patterns. Mon. Wea. Rev., 112, 638-651.

Rowson, D. R., and S. J. Colucci, 1992: Synoptic climatology of thermal low-pressure systems over south-western North America. Int. J. Climatol., 12, 529-545.

Stensrud, D. J., R. L. Gall, S. L. Mullen, and K. W. Howard, 1995: 
Model climatology of the Mexican monsoon. J. Climate, 8, Tang, M., and E. R. Reiter, 1984: Plateau monsoons of the Northern $1775-1794$.

— and M. K. Nordquist, 1997: Surges over the Gulf of California during the Mexican monsoon. Mon. Wea. Rev., 125, $417-437$ Hemisphere: A comparison between North America and Tibet. Mon. Wea. Rev., 112, 617-637.

Tucker, D. F., 1993: Diurnal precipitation variations in south-central New Mexico. Mon. Wea. Rev., 121, 1979-1991. 